\title{
Assessment of Oxidative Stress Changes in Serum and Follicular Fluid in Relevance to GnRH Rival Protocol in Iraqi Infertile Ladies Undergoing ICSI
}

\author{
Fatimah Abdulrazaq Raheem, Hayder A. L. Mossa, Wasan A.Abdulhamed, and Liqaa R. Altamimi
}

\begin{abstract}
Background: Literary works about the role of rival convention in relationship with oxidative pressure are opposing and there is no reasonable agreement in distributed ripeness articles about the role of opponent reproduction convention with this respect. In reality, a few creators support the presence of expanded oxidative initiated oocyte harm in ladies experiencing ART's; regardless, others have denied such a perception. Hence, the present investigation was arranged so as to think about the conceivable oxidative or hostile to oxidative potential controlled by foe convention.

Aim of the study: The aim of the current study was to evaluate the serum and follicular ROS concentration in women undergoing ICSI contrasted between two groups, one receiving conventional antagonist protocol and the other receiving conventional agonist protocol.

Patients and Methods: The current case control study included two groups of subfertile women. The study group included 57 women receiving antagonist protocol, whereas, the control group included 10 subfertile women receiving agonist protocol. The study was carried out at High Institute of Infertility Diagnosis and Assisted Reproductive Technologies at Al- Nahrain University. The study started on April 2018 and extended to March 2019. Women in both groups were subjected to ICSI procedure according to procedures and techniques adopted in High Institute of Infertility Diagnosis and Assisted Reproductive Technologies at Al- Nahrain University with a single basic difference concerning the ovarian stimulation protocol.
\end{abstract}

Results: Overall clinical pregnancy rate was $44.7 \%$ being significantly higher in antagonist group in comparison with agonist group $50.9 \%$ versus $10.01 \%$, respectively $(P=0.019)$. There was no significant difference in the concentration of ROS at cycle day 2 between antagonist and agonistgroups $(P=$ $0.561)$. There was highly significant difference in the serum concentration of ROS at day of ova pickup between antagonist and agonist groups $(P=0.009)$; being less in antagonistgroup and there was highly significant difference in the follicular fluid concentration of ROS between antagonist and agonist groups $(P=0.003)$; being less in antagonist group.

Conclusions: Antagonist protocol is associated with significantly higher positive pregnancy outcome in comparison

Published on December 23, 2019.

Fatimah Abdulrazaq Raheem, High Institute of Infertility Diagnosis and Assisted Reproductive Technologies, Al-Nahrain University, Department of Clinical Reproductive Physiology, Baghdad, Iraq.

Hayder A. L. Mossa, High Institute of Infertility Diagnosis and Assisted Reproductive Technologies, Al-Nahrain University, Department of Clinical Reproductive Physiology, Baghdad, Iraq.

(e-mail: haydermossa@googlemail.com).

Wasan A.Abdulhamed, High Institute of Infertility Diagnosis and Assisted Reproductive Technologies, Al-Nahrain University, Department of Clinical Reproductive Physiology, Baghdad, Iraq.

Liqaa R. Altamimi, Baghdad Specialist Center for Fertility and IVF, Baghdad, Iraq. with agonist protocol because of the anti-oxidant effect attributed to antagonist use.

Index Terms - Oxidative stress, Antagonist protocol, ICSI

\section{INTRODUCTION}

Unproductiveness is one of the essential restorative issues that are looked by early married couples far and wide $(1,2)$. Moreover, the impact of this issue is getting the opportunity to be basic in our overall population by virtue of social examples toward deferring time of marriage. Thusly, the objective of helped conceptive advances is composed toward constraining the significance of such medicinal issue in the system in like manner keeping up a key good ways from unwanted opposing effects in related with readiness helps (3).

In perspective on clinical observation in the national wealth associations that rival show is connected with better readiness results, the present examination was masterminded and finished to understand potential instruments related with better productivity brings about association with adversary affectation show. Oxidative weight and free outrageous harm has been extensively examined in association with a grouping of therapeutic issues in present day medicate $(4$, 5). It has been associated with developing procedure, metabolic issue, ischemic coronary sickness, cerebrovascular incidents, safe issue, neoplastic issue and wealth issues $(4,5)$. Oxidative stress in the field of productivity has been extensively considered in association with sperm properties and male subfertility; regardless, the appraisal of oxidative stress in association with oocyte characteristics and women subfertility is far not as much as that stressed over male subfertility (6). Compositions about the activity of foe show in association with oxidative weight are contradicting and there is no indisputable accord in conveyed readiness articles about the activity of adversary reenactment show with this regard $(7,8)$. Certainly, a couple of makers bolster the nearness of extended oxidative started oocyte hurt in women encountering ART's; notwithstanding, others have denied such an observation $(7,8)$. Thus, the present assessment was orchestrated in order to consider the possible oxidative or against oxidative potential constrained by rival show.

\section{Patients And Methods:}

The present case control study included two social occasions of subfertile women. The assessment social affair included 57 women getting enemy show, however, the control get-together included 10 subfertile women tolerating 
agonist show. The examination was done at High Institute of Infertility Diagnosis and Assisted Reproductive Technologies at Al-Nahrain University. The assessment started on April 2018 and loosened up to March 2019. Women in the two social occasions were presented to ICSI technique as demonstrated by methodologies and methodology grasped in High Institute of Infertility Diagnosis and Assisted Reproductive Technologies at AlNahrain University with a singular crucial complexity concerning the ovarian impelling show.

Components fused into the present examination were measurement characteristics, age, weight record, term of vanity, purpose behind fruitlessness and sort of infertility, benchmark hormonal levels, oocytes characteristics and embryo characteristics. Serum ROS center was assessed at cycle day 2 and at day of oocyte recuperation, while, follicular fluid ROS obsession was evaluated at day of oocyte recuperation in a manner of speaking. Biochemical estimation of ROS was finished by the bearings of the giving association. The basic outcome was pregnancy rate and assistant outcomes included oocyte and creating life properties.

Moral support was gotten from moral underwriting board and a verbal consent was obtained for each part. Data where by then changed into a SPSS structure 23 spread sheet for inspiration driving quantifiable examination. Data were dismembered, shortened and shown using genuine quantifiable gadgets and the level of centrality was set at $\mathrm{P} \leq$ 0.05. The fundamental confinement in the present assessment was the issue in securing subfertile women encountering agonist show. Figures

As said, to insert images in Word, position the cursor at the insertion point and either use Insert | Picture | From File or copy the image to the Windows clipboard and then Edit Paste Special | Picture (with "Float over text" unchecked).

The authors of the accepted manuscripts will be given a copyright form and the form should accompany your final submission.

\section{RESULTS}

The general characteristics of subfertile women took on the present assessment, requested agreeing into foe and agonist social occasions, are appeared in table 1 . There was no immense difference between the two social affairs in any of the characteristics.

The real examination in the present assessment has been established on fuse of 67 subfertile women encountering helped proliferation as ICSI, 57 women got rival show (set apart as social occasion 1), while 10 women got agonist show (named as get-together 2). At the completion of the examination, 29 women in pack 1 (adversary gathering) have winning to get clinically pregnant, thus the clinical pregnancy pace of social occasion 1 was $50.9 \%$; while only a single women in bundle 2 (agonist gathering) achieved positive clinical pregnancy with a pregnancy pace of 10.0 $\%$. Considering all model a single assembling, the clinical pregnancy rate will be 30 out of 67 (44.7\%); what makes a difference was basic $(\mathrm{P}=0.019)$.

The serum centralization of ROS at cycle day 2 everything considered, similar to center and between quartile broaden, was $1.59(0.38) \mathrm{ng} / \mathrm{ml}$, that of adversary social occasion was $1.59(0.37) \mathrm{ng} / \mathrm{ml}$ and that of agonist get-together was $1.55(0.26) \mathrm{ng} / \mathrm{ml}$; there was no vital complexity in the union of ROS at cycle day 2 among foe and agonist get-togethers $(\mathrm{P}=0.561)$, table 2 . The serum combination of ROS at day of ova pickup everything considered, similar to center and between quartile go, was $1.11(1.02) \mathrm{ng} / \mathrm{ml}$, that of enemy social affair was 1.08 (1.04) $\mathrm{ng} / \mathrm{ml}$ and that of agonist get-together was 1.44 $(0.31)) \mathrm{ng} / \mathrm{ml}$; there was significantly critical qualification in the serum centralization of ROS at day of ova pickup among opponent and agonist get-togethers $(\mathrm{P}=0.009)$; being less in foe gathering, table 2. The follicular fluid assembly of ROS everything considered, similar to center and between quartile expand, was $1.13(0.60) \mathrm{ng} / \mathrm{ml}$, that of foe social occasion was $1.08(0.64) \mathrm{ng} / \mathrm{ml}$ and that of agonist gettogether was $1.45(0.21) \mathrm{ng} / \mathrm{ml}$; there was significantly immense complexity in the follicular fluid centralization of ROS among adversary and agonist get-togethers ( $\mathrm{P}=$ 0.003 ); being less in opponent get-together, table 2 .

The level of serum cycle day 2 ROS was insignificant assorted among pregnant and non pregnant ladies, 1.54 (0.38) $\mathrm{ng} / \mathrm{ml}$ versus $1.59(0.38) \mathrm{ng} / \mathrm{ml}$, independently $(\mathrm{P}=$ 0.865 ), table 3 . Nevertheless, serum ROS at day of ova pickup was through and through lower in women with positive pregnancy in connection with women with negative pregnancy, $0.61(0.81) \mathrm{ng} / \mathrm{ml}$ versus $1.29(0.52) \mathrm{ng} / \mathrm{ml}$, independently $(\mathrm{P}=0.001)$, table 3 . Also, follicular fluid ROS at day of ova pickup was on a very basic level lower in women with positive pregnancy in assessment with women with negative pregnancy, $0.92(0.50) \mathrm{ng} / \mathrm{ml}$ versus 1.37 $(0.45) \mathrm{ng} / \mathrm{ml}$, independently $(\mathrm{P}=0.001)$, table 3 .

\section{Discussion AND CONCLUSIONS}

In the present examination, the pregnancy rate achieved in the social event of subfertile women on rival actuation show was basically higher than that practiced by women on agonist show, $50.9 \%$ versus $10.0 \%$, independently. One may battle that the amount of women on agonist show was a great deal of lower than that on rival show and this may have out and out impacted the clinical pregnancy bring about agonist gathering. Without a doubt, it is a method in our wealth establishment to grasp foe show since the clinical observation during the extended lengths of work in the foundation has given strong verification that enemy show is regularly associated with basically higher pregnancy result than agonist show. Of course, in the present examination, we use the non parametric test Fischer precise test which as a rule overcome the issue of little model size.

Directly how to explain the enormous difference in pregnancy rate between the two shows in the present examination. To the exclusion of everything else, the level of responsive oxygen species will be first chart and the trading of various components will be conceded into the accompanying moving toward fragments. The striking observation in the streams study was that the level of ROS, both in serum and follicular fluid, in adversary bundle on day of ova pickup was by and large lower than that of agonist gathering. By and by, the two social events has gotten unfriendly to oxidant treatment for a for all intents and purposes indistinguishable time period and in a part that 
is close, demonstrate by the nonattendance of immense qualification in the term and bit of foes of oxidants got by subfertile women chose the two get-togethers. Thusly, it is no satisfactory, to the extent estimations, to characteristic the differentiation in serum and follicular fluid assembly of ROS, to the sole usage of foes of oxidants and there must be another factor that expedited extra immense diminishing of ROS center in the adversary social occasions. In our examination, the undoubtedly explanation is that foe show has without any other individual the likelihood to convey this immense abatement in ROS level.

In one assessment did in Clinic of Gynecology and Obstetrics, Clinical Center of Serbia, near relationship was made and the results exhibited that the ovarian induction show was neither related with lavishness parameters nor related with all around oxidative weight parameters (7). The results of our assessment are restricting to delayed consequences of the last examination (7). On the other hand, our results are questionable to that seen by Celik et al. (8), who found that foe show was connected with by and large more oxidative stress than agonist show reliant on estimation of serum and follicular fluid oxidative and threatening to oxidative markers. In a further report, the counter oxidant activity was lower in enemy show conversely with agonist show (9), a seeing that shows up as restricting to our recognition. Regardless, in a further report, there was no basic qualification among serum and follicular fluid oxidative stress among agonist and foe show (10). As of recently, and after serious interest in the available dispersed article, we can say and to the extent we could realize this is the chief concentrate to show basically cut down combination of ROS in adversary social affairs in relationship with agonist gathering.

In addition, in the present we had the alternative to show that positive pregnancy result was in a general sense associated with low level of serum and follicular fluid ROS obsession. This finding is as per different various makers who saw that serum and follicular fluid oxidative weight was in a general sense lower in women with successful pregnancy in relationship with the people who fail to achieve pregnancy following ART's $(7,10,11)$. In this way, we conjecture that one of the fundamental explanation for our results is that adversary show was connected with less oxidative weight and along these lines better pregnancy result.

The loss of agreement among oxidant and malignant growth counteractive action operator molecules in serum and in follicular fluid (FF) has been prescribed to be liable for abnormal oocyte improvement, in light of DNA and cell film hurt, which would then achieve lessened egg quality, yet also in changed treatment, hatchling quality, implantation, and embryonic progression $(12,13)$. A couple of assessments have nitty gritty signs of oxidative stress in serum and in the FF of unprofitable women (14).

A couple of makers suggested that oxidative weight changes the oocyte and hatchling quality, and in this way the treatment rate (15), while various makers (11) declared that signs of lipid peroxidation in FF don't reflect the regenerative capacity of oocytes. In addition, it has been demonstrated that higher ROS levels and signs of lipid peroxidation (16) are accessible in women who ended up pregnant by IVF, yet furthermore that a higher full scale malignancy aversion specialist limit (TAC) is connected with extended treatment potential in women encountering IVF (11). As such, there doesn't yet exist a general accord at work of oxidative stress in the methods controlling planning and embryonic headway, nor on the association between the redox parameters in blood and $\mathrm{FF}$, and their effects on oocyte, nascent living being quality, in conclusion IVF results.

\section{REFERENCES}

[1] Vander Borght M, Wyns C. Fertility and infertility: definition and epidemiology. Clin Biochem. 2018;62:2-10.

[2] Agarwal A, Mulgund A, Hamada A, Chyatte MR. A unique view on male infertility around the globe. Reprod Biol Endocrinol. 2015;13:37.

[3] Huang JY, Rosenwaks Z. Assisted reproductive techniques. Methods in molecular biology. 2014;1154:171-231.

[4] Liguori I, Russo G, Curcio F, et al. Oxidative stress, aging, and diseases. Clin Interv Aging. 2018;13:757-772.

[5] Pizzino G, Irrera N, Cucinotta M, et al. Oxidative Stress: Harms and Benefits for Human Health. Oxid Med Cell Longev. 2017;2017:8416763.

[6] Azher S. Hindal, Hayder A. L. Mossa , Muayad S. Abood. Reactive Oxygen Species Levels in Seminal Plasma in a Sample of Iraqi Infertile Men using Advanced Stimulatory Method for Activation of Spermatozoa. International Journal of Medical Research \& Health Sciences (2018), Volume 7, Issue 12, 51 - 55.

[7] Tulić L, Vidaković S, Tulić I, Curčić M, Stojnić J, Jeremić K. Oxidative Stress Markers in GnRH Agonist and Antagonist Protocols in IVF. J Med Biochem. 2017;36(2):163-170.

[8] Celik E, Celik O, Kumbak B, et al. A comparative study on oxidative and antioxidative markers of serum and follicular fluid in $\mathrm{GnRH}$ agonist and antagonist cycles. J Assist Reprod Genet. 2012;29(11):1175-1183.

[9] Aydogan Mathyk B1, Aslan Cetin B2, Vardagli D3, Zengin E4, Sofiyeva N5, Irez T6, Ocal P7. Comparison of antagonist mild and long agonist protocols in terms of follicular fluid total antioxidant capacity. Taiwan J Obstet Gynecol. 2018 Apr;57(2):194-199.

[10] Siristatidis C., Askoxylaki M., Varounis C., Kassanos D., Chrelias C. E-selectin, resistin and reactive oxygen species levels in $\mathrm{GnRH}$ agonist and -antagonist protocols in IVF/ICSI: A prospective cohort study. J. Assist. Reprod. Genet. 2015;32:959-967.

[11] Becatti M, Fucci R, Mannucci A, et al. A Biochemical Approach to Detect Oxidative Stress in Infertile Women Undergoing Assisted Reproductive Technology Procedures. Int J Mol Sci. 2018;19(2):592.

[12] Devine P.J., Perreault S.D., Luderer U. Roles of reactive oxygen species and antioxidants in ovarian toxicity. Biol. Reprod. 2012;86

[13] Agarwal A., Aponte-Mellado A., Premkumar B.J., Shaman A., Gupta $\mathrm{S}$. The effects of oxidative stress on female reproduction: A review. Reprod. Biol. Endocrinol. 2012;10

[14] Agarwal A., Gupta S., Sharma R. Oxidative stress and its implications in female infertility-A clinician's perspective. Reprod. Biomed. Online. 2005;11:641-650.

[15] Du Plessis S., Makker K., Desai N. Impact of oxidative stress on IVF. Exp. Rev. Obstet. Gynecol. 2008;3:539-554.

[16] Pasqualotto E.B., Agarwal A., Sharma R.K., Izzo V.M., Pinotti J.A., Joshi N.J., Rose B.I. Effect of oxidative stress in follicular fluid on the outcome of assisted reproductive procedures. Fertil. Steril. 2004;81:973-976. 
TABLE 1: Demographic characteristics of subfertile women undergoing ICSI

\begin{tabular}{|c|c|c|c|c|}
\hline Characteristic & $\begin{array}{l}\text { Total } \\
n=57\end{array}$ & $\begin{array}{c}\text { Group } \\
\text { (Antagonist) } \\
n=57\end{array}$ & $\begin{array}{l}\text { Group } 2 \text { (Agonist) } \\
n=10\end{array}$ & $P$ \\
\hline \multicolumn{5}{|l|}{ Age } \\
\hline$\pm \mathrm{SD} \quad$ Mean & $28.97 \pm 5.14$ & $29.30 \pm 5.22$ & $27.10 \pm 4.38$ & \multirow{2}{*}{$\begin{array}{l}0.215 \dagger \\
\mathrm{NS}\end{array}$} \\
\hline Range & $18-36$ & $18-36$ & $20-35$ & \\
\hline (\%) $\quad<35, n$ & $55(82.1 \%)$ & $46(80.7 \%)$ & $9(90.0 \%)$ & \multirow{2}{*}{$\begin{array}{l}0.676 \mathrm{~F} \\
\mathrm{NS}\end{array}$} \\
\hline$\quad \geq 35, n$ & $12(17.9 \%)$ & $11(19.3 \%)$ & $1(10.0 \%)$ & \\
\hline \multicolumn{5}{|l|}{ BMI } \\
\hline$\pm \mathrm{SD} \quad$ Mean & $24.24 \pm 2.69$ & $24.15 \pm 2.76$ & $24.71 \pm 2.33$ & \multirow{2}{*}{$\begin{array}{l}0.550 \dagger \\
\text { NS }\end{array}$} \\
\hline Range & $19.40-35.30$ & $19.40-35.30$ & $19.50-28.10$ & \\
\hline$n(\%) \quad$ Normal, & $41(61.2 \%)$ & $36(63.2 \%)$ & $5(50.0 \%)$ & \multirow{2}{*}{$\begin{array}{l}0.493 \mathrm{~F} \\
\mathrm{NS}\end{array}$} \\
\hline ght, $n(\%)$ Overwei & $26(38.8 \%)$ & $21(36.8 \%)$ & $5(50.0 \%)$ & \\
\hline \multicolumn{5}{|l|}{ Causes of infertility } \\
\hline $\begin{array}{l}\text { Male } \\
\text { factor, } n(\%)\end{array}$ & $27(40.3 \%)$ & $24(42.1 \%)$ & $3(30.0 \%)$ & \multirow{4}{*}{$\begin{array}{l}0.428 ¥ \\
\text { NS }\end{array}$} \\
\hline $\begin{array}{l}\text { Female } \\
\text { factor, } n(\%)\end{array}$ & $25(37.3 \%)$ & $19(33.3 \%)$ & $6(60.0 \%)$ & \\
\hline $\begin{array}{ll} & \text { Combine } \\
\mathrm{d}, n(\%) & \end{array}$ & $1(1.5 \%)$ & $1(1.8 \%)$ & $0(0.0 \%)$ & \\
\hline ned, $n(\%){ }^{\text {Unexplai }}$ & $14(20.9 \%)$ & $13(22.8 \%)$ & $1(10.0 \%)$ & \\
\hline \multicolumn{5}{|l|}{$\begin{array}{l}\text { Antioxidant } \\
\text { administration onset }\end{array}$} \\
\hline $\begin{array}{l}\text { Mean } \\
\pm \text { SD (Months) }\end{array}$ & $2.03 \pm 0.82$ & $2.05 \pm 0.81$ & $1.90 \pm 0.88$ & \multirow{2}{*}{$\begin{array}{l}0.589 \dagger \\
\mathrm{NS}\end{array}$} \\
\hline Range & $1-3$ & $1-3$ & $1-3$ & \\
\hline \multicolumn{5}{|l|}{$\begin{array}{cc}\begin{array}{c}\text { Duration } \\
\text { antagonist administration }\end{array} & \text { of } \\
\end{array}$} \\
\hline \pm SD (days) & --- & $3.53 \pm 0.73$ & --- & \multirow{2}{*}{---} \\
\hline Range & --- & $2-5$ & --- & \\
\hline \multicolumn{5}{|l|}{$\begin{array}{l}\text { Duration of agonist } \\
\text { administration }\end{array}$} \\
\hline $\begin{array}{l}\text { Mean } \\
\pm \mathrm{SD} \text { (days) }\end{array}$ & --- & --- & $3.80 \pm 0.79$ & \multirow{2}{*}{--} \\
\hline Range & --- & --- & $3-5$ & \\
\hline
\end{tabular}

TABLE 2: The concentration of reactive oxygen species (ROS) in women undergoing ICSI according to antagonist protocol and categorized according to clinical pregnancy outcome

\begin{tabular}{|c|c|c|c|c|}
\hline ROS concentration $(\mathrm{ng} / \mathrm{ml})$ & $\begin{array}{l}\text { Total } \\
n=67\end{array}$ & $\begin{array}{l}\text { Group } 1 \text { (Antagonist) } \\
n=\mathbf{5 7}\end{array}$ & $\begin{array}{l}\text { Group } 2 \text { (Agonist) } \\
n=10\end{array}$ & $P €$ \\
\hline \multicolumn{5}{|l|}{ Serum level at CD2 } \\
\hline Range & $1.18-22.53$ & $1.18-22.53$ & $1.39-16.42$ & $\begin{array}{l}0.561 \\
\mathrm{NS}\end{array}$ \\
\hline \multicolumn{5}{|l|}{ Serum level at day of ova pickup } \\
\hline Median (IQR) & $1.11(1.02)$ & $1.08(1.04)$ & $1.44(0.31)$ & \multirow{2}{*}{$\begin{array}{l}0.002 \\
\mathrm{HS}\end{array}$} \\
\hline Range & $0.04-13.64$ & $0.04-13.64$ & $1.18-13.64$ & \\
\hline \multicolumn{5}{|l|}{ Follicular fluid level } \\
\hline Median (IQR) & $1.13(0.60)$ & $1.08(0.64)$ & $1.45(0.21)$ & \multirow{2}{*}{$\begin{array}{l}0.003 \\
\mathrm{HS}\end{array}$} \\
\hline Range & $0.08-17.92$ & $0.08-16.45$ & $1.19-17.92$ & \\
\hline
\end{tabular}


TABLE 3: Correlation of clinical pregnancy outcome to reactive oxygen species (ROS) concentration

\begin{tabular}{|l|l|l|l|}
\hline ROS & $\begin{array}{l}\text { Positive pregnancy } \\
\boldsymbol{n}=\mathbf{3 0}\end{array}$ & $\begin{array}{l}\text { Negative pregnancy } \\
\boldsymbol{n}=\mathbf{3 7}\end{array}$ & $\boldsymbol{P} €$ \\
\hline Serum at cycle day 2 & $1.54(0.38)$ & $1.59(0.38)$ & 0.865 \\
NS
\end{tabular}

$n$ : number of cases; IQR: inter-quartile range; $€$ : Mann Whitney U test; NS: not significant at $P \leq 0.05$; HS: highly significant at $P \leq 0.01$ 